\title{
Prevalence of pica among pregnant women attending antenatal clinic in a tertiary facility in Nigeria
}

\author{
Muhammad Baffah Aminu, ${ }^{1}$ Alkali Mohammed, ${ }^{2}$ Bala Audu Muhammed, ${ }^{1}$ Toyin Abdulrazak, ${ }^{3}$ \\ Aniobi Chinedu ${ }^{1}$ \\ Departments of ${ }^{1}$ Obstetrics and Gynecology, ${ }^{2}$ Internal Medicine, ${ }^{3}$ Laboratory Medicine, Abubakar Tafawa \\ Balewa University Teaching Hospital, Bauchi, Nigeria
}

\begin{abstract}
One of the unusual symptoms observed among pregnant women is the aversion for non-food substances like sand, clay and ice. Pica is a form of eating disorder characterised by these symptoms. It occurs commonly in children and among pregnant women. This study aims to determine the prevalence and associated factors for Pica among booked patients in our institution. A prospective study was conducted among pregnant women at booking aged 11-45 years at the ATB University teaching Hospital Bauchi between 1st February to 31 st of July 2019. All pregnant women who gave their consent were interviewed using a pretested questionnaire. The biodata, risk factors for Pica, occurrence in childhood and other social habits were recorded. The result showed a prevalence rate of pica at $38.9 \%$ with a craving for ice $(18.7 \%)$, sand $(14.7 \%)$ and others (55.11\%). Pica was observed more in the day time (afternoon and evening) and most women having pica had a low level of education. Even though the prevalence of Pica appeared low in our environment, adequate counselling and appropriate treatment of women with this condition should be given more priority.
\end{abstract}

\section{Introduction}

Majority of pregnant women experience changes in their normal feeding patterns. ${ }^{1}$ Pica is a form of eating disorder that is char-

Correspondence: Muhammad Baffah Aminu, Department of Obstetrics and Gynecology, Abubakar Tafawa Balewa University Teaching Hospital, Bauchi, Nigeria.

Tel.: +234.7037147717 .

E-mail: aminubaffahmuhammad@gmail.com

Key words: Pregnant women, pica, counselling.

Contributions: The authors contributed equally.

Conflict of interest: The authors declare no potential conflict of interest.

Funding: None.

Received for publication: 4 October 2019.

Accepted for publication: 10 November 2019.

This work is licensed under a Creative Commons Attribution NonCommercial 4.0 License (CC BY-NC 4.0).

${ }^{\circ}$ Copyright: the Author(s), 2019

Licensee PAGEPress, Italy

Annals of African Medical Research 2019; 2:89

doi:10.4081/aamr.2019.89 acterized by persistent desire and intentional consumption of substances that the consumer does not define as food, and is a largely common phenomenon that has been documented in nearly every culture. ${ }^{2,3}$ It is a term that emanates from the Latin word for "magpie", a bird that belongs to the raven family, whose scientific name is pica pica. ${ }^{4}$ The magpie is well- known for its greedy voracious appetite and for eating or trying to eat a variety of substances, including several things that are not food. ${ }^{4}$ Some other substances that can be ingested include, sand, ice, clay and chalk.

This perversion of appetite is not a recent problem, and the ingestion of non- nutritious substance can be traced as far back as the ancient Greek civilization, in 40BC, with the use of clay to cure diseases or treat poisoning already documented. ${ }^{5}$ It is a worldwide problem that has no barrier of age, sex, race or geographic region. ${ }^{6}$ This condition has been reported in Australia, Canada Israel, Iran, Uganda, Wales and Jamica. ${ }^{7}$

Published data reveals a prevalence of Pica between 0.02 to $74 \%{ }^{1}$ In a study conducted among rural pregnant women in Jamaica in 1992, it was noted that 15 of the 38 pregnant women questioned, reported craving to ingest stone. ${ }^{7}$ Similarly, in a study to determine the characteristics of pica practice during pregnancy in Argentinean women, it was found that pica practice was prevalent in $23.2 \%$ of the 1014 women interviewed, with Pagophagia the commonest form. ${ }^{8}$ In Tehran, Iran, pica was prevalent among $8.3 \%$ of the studied population, with pagophagia the most common form. ${ }^{1}$ In Malawi, it was reported to be surprising for a pregnant woman not to practice pica, since this is how a woman knows that she is pregnant. ${ }^{9}$ Also, a high prevalence has been reported in Tanzania (63. 7\%), Kenya (73\%), Nigeria (50\%). ${ }^{10,11}$

There are 3 main forms of pica. ${ }^{12}$ One type is geophagy or geophagia, which is the consumption of earth, including soil or other earth- rich items such as adobe, clay, pottery or beam stones. The second is amylophagia (amylophagia), which is the consumption of raw starches, including corn starch, laundry starch, raw rice and floor. The third is pagophagia, for the consumption of freezer frost or ice. ${ }^{12}$ Polypica on the other hand refers to the consumption of more than one non- nutritive substance during the same period. ${ }^{4}$

The exact aetiology of pica is unknown. ${ }^{1}$ It has been linked to an increase in parasitic infection, electrolyte disturbance, GIT complication, oral and dental injury, lead poisoning and iron deficiency anemia (IDA). ${ }^{13-15}$

Numerous complications can result from this pervasive eating habit. ${ }^{7}$ It has been associated significantly with lower maternal haemoglobin levels at delivery. ${ }^{7}$ It can lead to hyper or hypokalaemia, lead poisoning, and excessive phosphorous. ${ }^{16}$ Also, there has been an observed decrease in the head circumference of infants whose mothers had pica during pregnancy than those of non-pica women. ${ }^{16}$

In relation to pica treatment, it has been suggested that the practice can be reversed by the administration of iron supplements. Nevertheless, many aspects involved in pica health approach are still unknown. ${ }^{3}$ 
This study of pica among pregnant women in ATBUTH was conducted to determine its prevalence in this region with the view to offer solutions to women with this symptom.

\section{Materials and Methods}

The study design was a prospective type and conducted at the Abubakar Tafawa Balewa University Teaching Hospital (ATBUTH), Bauchi state. Participants in this study included all consecutive pregnant women who attended the Antenatal clinic (ANC) from February 1st, 2019 to July 31th, 2019, for their routine ANC clinic and gave their consent to participate in the study. The evaluation protocol included biodata, risk factors and complications of Pica.

\section{Study population}

The study population were pregnant women attending antenatal clinic (ANC) at the ATBUTH, Bauchi. The inclusion criteria were all pregnant women within the reproductive age group who are healthy and had no chronic medical condition.

\section{Sample size}

This was calculated using the fisher's formula with the $50 \%$ prevalence rate quoted by Sule et al. in Zaria $2001 .^{1}$

$$
\mathrm{N}=\mathrm{z}^{2} \mathrm{pq} / \mathrm{d}^{2}
$$

where $\mathrm{N}$ - minimum sample size

z - Standard deviation 1.96 at $95 \%$ confidence interval

$\mathrm{p}$ - Proportion of target population

q $-1-p$

$\mathrm{d}$ - degree of accuracy which is 0.005

$$
\mathrm{N}=1.962 \times 0.5 \times 0.5 /(0.005)^{2}
$$

$\mathrm{N}=422$ participants

\section{Data collection}

A pre-tested structured questionnaire was used to collect data from each study participant in line with the objectives of the study. Personal identifiers were not used on the questionnaires. Data collected during the interview, were coded, entered, verified, and analysed using SPSS version 21 (IBM, USA).

Ethical approval was sought and granted by the Health research and ethical committee of the Abubakar Tafawa Balewa University Teaching Hospital, Bauchi. All information and data obtained were kept confidential.

\section{Results}

The biodata of the participating pregnant women is presented in Table 1 . The majority of the respondents were between the ages of 21 and 35 years $(61 \%)$. The highest percentages of pregnant women were married (97\%) and multigravida (68.8\%). More than half of the women are housewives $(62.2 \%)$ with tertiary level of education $(51 \%)$.

Sixty-one $(61 \%)$ of the pregnant women had not had pica, given a prevalence rate of $38.9 \%$ in the study.

Some of the major non-food substances ingested these women are sand $(14.7 \%)$ and ice $(18.7 \%)$.
The highest prevalence of pica was observed during Morning (18.7\%), afternoon (17.61\%) and evening (19.3\%) hours with less prevalence at night $(14.77 \%)$.

\section{Discussions}

Pica occurs when an individual inappropriately ingests nonfood substance over a period of a month. ${ }^{17}$ It affects pregnant women, children and the people with defective cognitive functions, ${ }^{18}$ substance abuse and impulse control disorders. ${ }^{19}$ In this study, pica was found to be commoner among women in their second and third decade (Table 1). This is not surprising since these women are almost at the peak of their reproductive career and therefore more likely to embark on pregnancy than their younger or older counterpart. In addition, Pica was also commoner among multiparous participants as observed in the study, this will further buttress the fact earlier stated in relation to age, as most of them would have had previous pregnancies in the past.

As opposed to the study by Sule et al. in Zaria $(50 \%)^{10}$ and Faustina et al. in Kumasi $(47 \%){ }^{20}$ our study observed the prevalence of Pica to be lower (38.9\%) as shown in Figure 1, with the majority of the respondents not having the craving, this may be due to improvement in the nutritional status of these women and the fact that many of them would have started haematinics even before booking their pregnancy because of the ongoing awareness on iron supplementation especially in pregnancy being advocated for. Even though a similar study in Iran and Kenya have quoted a much lower prevalence figure of $8.3 \%$ and $27.4 \%$ respectively, ${ }^{21,22}$ the regional variation, as well as the small sample size in those studies, may account for the higher figure observed in our study.

Another possible reason for the low prevalence of Pica in this

Table 1. Socio-demographic characteristics of respondents $(n=452)$.

\begin{tabular}{lcc} 
Characteristic & Frequency & $\%$ \\
Age-Group & & \\
$11-15$ & 1 & 0.22 \\
$16-20$ & 35 & 7.74 \\
$21-25$ & 142 & 31.42 \\
$26-30$ & 131 & 28.98 \\
$31-35$ & 96 & 21.24 \\
$36-40$ & 43 & 9.51 \\
$41-45$ & 4 & 0.88 \\
Marital Status & & \\
Married & 440 & 97.35 \\
Single & 7 & 1.55 \\
Divorced & 2 & 0.44 \\
Widowed & 3 & 0.66 \\
\hline Parity & & \\
Primigravida & 89 & 19.70 \\
Multigravida & 311 & 68.80 \\
Grand multipara & 52 & 11.50 \\
Educational Status & & \\
Primary & 25 & 5.50 \\
Secondary & 157 & 34.70 \\
Tertiary & 234 & 51.80 \\
Islamiyah & 36 & 8.00 \\
\hline Occupation & & \\
House Wife & 281 & 62.20 \\
Civil Servant & 88 & 19.50 \\
Others & 83 & 18.40 \\
\hline
\end{tabular}


study could be because of the high literacy level of the majority of the respondents $(51 \%$ had tertiary and $34 \%$ had secondary level education). This plausible explanation agrees with the findings of a study in Iran where the lowest prevalence of $9.5 \%$ of the condition was seen in those with higher education, ${ }^{21}$ this suggests that the awareness level for Pica seem to be higher in educated women that those who are poorly educated further buttressing the role of education in lowering the prevalence of pica.

Unlike other studies in Oman and Denmark, ${ }^{23,24}$ the ingestion of other substances like paper, hair, paint, drywall and stones etc was reported by more than half (55\%) of all the participants with a

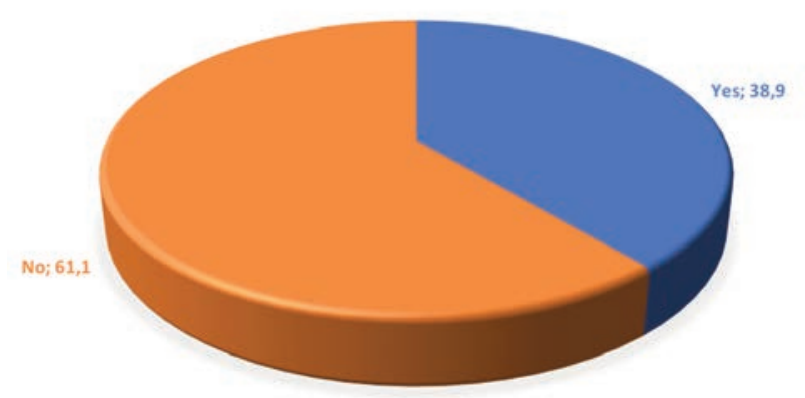

Figure 1. Respondents Responses on pica $(n=452)$.

Table 2. Substances Injected reported by respondents.

\begin{tabular}{lcc} 
Variables & Frequency & $\%$ \\
Soil & 13 & 7.39 \\
Sand & 26 & 14.77 \\
\hline Ice & 33 & 18.75 \\
Ashes & 3 & 1.70 \\
\hline Chalk & 3 & 1.70 \\
Soap & 1 & 0.57 \\
\hline Others & 97 & 55.11 \\
Total & 176 & 100.00 \\
\hline
\end{tabular}

Table 3. Frequency of ingesting substances reported by respondents $(n=176)$.

\begin{tabular}{lcc} 
Variables & Frequency & $\%$ \\
Morning & 33 & 18.75 \\
Afternoon & 31 & 17.61 \\
\hline Evening & 34 & 19.32 \\
At Night & 26 & 14.77 \\
\hline Any Time & 52 & 29.55 \\
Total & 176 & 100.00 \\
\hline
\end{tabular}

Table 4. Characteristics of pregnant women who reportedly practicing pica $(\mathbf{n}=176)$.

\begin{tabular}{lcccc} 
Characteristics & Yes & $\%$ & No & $\%$ \\
PICA in Childhood & 84 & 18.584 & 92 & 20.35 \\
Family or Friend with PICA History & 121 & 26.77 & 55 & 12.17 \\
\hline
\end{tabular}

craving for ice also as a common finding (Table 2). This agrees with a study in Tehran and Zahedan all in Iran where Pagophagia (ice ingestion) was about $76 \%$ and $53,7 \%$ respectively. ${ }^{22,25}$ Pagophagia appeared to have no age variation and not exclusive to pregnant women as demonstrated by a study in Sudan among young children with sickle cell disorders. ${ }^{17}$ This is in contrast to previously reported studies where geophagia (ingestion of sand) were commonly reported. The reason for this change may be the perceived danger associated with ingestion of sand by the participants in our study most of whom had tertiary level of education (Table 1). Previous studies have all documented the benefits of education in reducing the aversion for non-food substances in pregnancy

Among participants who reported Pica (176), the craving occurs most time in the morning (18.2\%), afternoons $(17.6 \%)$ and evenings (19.3\%) hours (Table 3$)$, these are periods where most women are active and alert, thus the disturbing symptoms of nausea, unpleasant smell and stomach aches that are the common reasons for Pica are at their peak and therefore requiring urgent solution. Little wonder that pica is not common at night largely because these are hours of sleep.

The occurrence of Pica is shrouded by lots of speculations ranging from nutritional, physiological and psycho-social theories, ${ }^{17}$ some have even speculated that Pica is indeed a form of OCDs (obsessive-compulsive Disorder). ${ }^{26}$

Also observed in this study is the predominance of Pica among women with family history, here it was noticed that $26.7 \%$ (Table 4) of the women that had pica during the study period had a friend or a family history of Pica, this was also the findings of Johnson and Derrick were pica was commoner among women that had family history in a culturally exposed communities. ${ }^{27}$ This finding further supports the observation made by Simpson et al. in 2000 that a family history of pica and its presence during childhood is a risk factor for pica in pregnancy. ${ }^{29}$ To this end, pica has been observed to be commoner among Afro-Americans and foreign-born women. ${ }^{24}$

\section{Conclusions}

Even though Pica prevalence was low in our environment, it should be noted that the majority of those who practice it tend to be secretive about it. Health care providers, therefore, should specifically inquire about it at booking especially in those with childhood history, since pica symptoms will remain unchanged unless they are specifically addressed.

\section{References}

1. Neda B, Rasa Z, Mostapa N, et al. Prevalence and risk factors for pica during pregnancy in Tehran, Iran. Spring Jnt Pol Switz 2015;1-8.

2. Mensah FO, Twomasi, P, Amonawonyo XK, et al. Pica Practise among pregnant women in the Kumasi metropolis of Ghana. Int Health J 2010;2:282-6.

3. Young SL, Khalfan SS, Farag TH, et al. Association of pica with anaemia and gastrointestinal distress among pregnant women in Zanzibar, Tanzania. Am J Trop Med Hyg 2010; $83: 144-51$.

4. Moore D, Sears D. Pica, Iron deficiency and the medical history. Am J Med 1994;97:390-3.

5. Woywodt A. Geophagia; the history of earth-eating. J Royal 
Soc Med 2002;95:143-6.

6. Sayetta RB. Pica. An overview. Am Fam Physician 1986;33:181-5.

7. Ellis CR, Schnoes CJ. Eating disorder; pica. Emed J 2002;3:112 .

8. Lopez LB, Marigual M, Martín N, et al. Characteristics of pica practice during pregnancy in a sample of Argentine women. $\mathrm{J}$ Obstet Gynaecol 2012;32:150-3.

9. Callaha KL. Pica. Geophagy and rock art; ingestion of powder and clay by humans and its implications the production of some rock art on a global basis. A paper read at the Philadelphia, SAA conference on April 8, 2000. Available from: http://www.oocities.org/athens/acropolis/5579/ pica.html.

10. Sule S. Madugu HN. Pica in pregnant women in Zaria, Nigeria, Niger J Med 2001;10:25-7.

11. Nyarohucha CN. Food cravings, aversions and pica among pregnant women in Dar es Salaam, Tanzania. Tanzan J Health Res 2009;11:29-34.

12. Young SL. Pica in pregnancy: new ideas about an old condition. Annu Rev Nutr 2010;30:403.

13. Boatin A, Wylie B, Singh MP, et al. Prevalence of and risk factors for pica among pregnant women in Chhattisgarh, India. Am J Obstet Gynaecol 2011;206:5299.

14. Thihalolipavan S, Candalla BM, Ehrlich J. Examining Pica in NYC pregnant women with elevated lead levels. Matern Child Health J 2013; 17:49-55.

15. Tsuyoshi HTM. A rapid recovery from pagophagia following treatment for iron deficiency anaemia and TMJ disorder accompanied by masked depression. Kawasaki Med J 2009:35:329-32.

16. Edward CH, Johnson AA, Knight EM, et al. Pica in an urban environment. J Nutr 1994;124:9545-25.

17. Ahmed FE, Gaboli HO, Attalla B. Pica among Sudanese children with sickle cell anemia. Basic Res J Med Clin Sci 2015;4:1-7.

18. Wang PY, Wang $X$, Zhang L, et al. Bezoar-induced small bowel obstruction: Clinical characteristics and diagnostic value of multi-slice spiral computed tomography. World J Gastroenterol 2015;21:9774.

19. Hartmann AS, Becker AE, Hampton C, Bryant-Waugh R. Pica and rumination disorder in DSM-5. Psychiatr Ann 2012;42:426-30.

20. Faustina O, Twumasi MP, Amenawonyo KX, et al. Pica Practice among Pregnant Women in the Kumasi Metropolis of Ghana. Int Health 2010;2:282-6.

21. Ezzeddin N, Zavoshy R, Noroozi M, et al. Prevalence and risk factors for pica during pregnancy in Tehran, Iran. Eat Weight 2015;20:457-63.

22. Kariuki L, Lambert C, Purwestri R, Biesalski HK. Trends and consequences of consumption of food and non-food items (pica) by pregnant women in Western Kenya. NFS J 2016;5:14.

23. Al-Sharbati MM, Zaidan ZA, Al-Hussaini A, Al-Khalili K. A strange type of Pica. J Sci Res Med Sci 2003;5:49-50.

24. Mikkelsen TB, Anderson AM, Olsen SF. Pica in pregnancy in a privileged population: myth or reality. Acta Obstetr Gynecol Scand 2006;85:1265-6.

25. Khoushabi F, Ahmadi P, Shadan MR, et al. Pica practices among pregnant women are associated with lower hemoglobin levels and pregnancy outcome. Open J Obstet Gynecol 2014:4:646.

26. Stein DJ, Bouwer C, Van Heerden B. Pica and the obsessivecompulsive spectrum disorders. 1996. Available from: http://scholar.sun.ac.za/handle/10019.1/7231

27. Hartmann AS, Becker AE, Hampton C, Bryant-Waugh R. Pica and rumination disorder in DSM-5. Psychiatr Ann 2012;42:426-30.

28. Mortazavi Z, Mohammadi M. Prevalence of pica in pregnant women referred to health care centers in Zahedan, Iran (20022003). Afr J Food Sci 2010;4:642-5.

29. Simpson E, Mull JD, Longley E, East J. Pica during pregnancy in low-income women born in Mexico. West $\mathrm{J}$ Med 2000;173:20. 